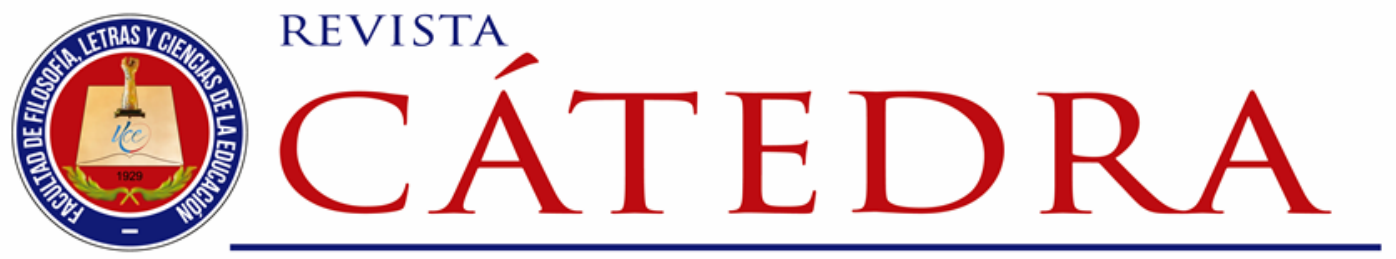

\title{
Programación neurolingüística como estrategia innovadora para la didáctica de la lengua y la literatura
}

\section{Neurolinguistic programming as an innovative strategy for language and literature teaching}

\author{
Michelle Riera-Flores \\ Universidad Central del Ecuador, Quito, Ecuador \\ michellesofiariera@gmail.com \\ https://orcid.org/0000-0002-7423-944X \\ Pablo Romo-Maroto \\ Universidad Central del Ecuador, Quito, Ecuador \\ promo@uce.edu.ec \\ https://orcid.org/0000-0002-2281-1352
}

(Recibido: 28/07/2020; Aceptado: 30/07/2020; Versión final recibida: 15/08/2020)

Cita del artículo: Riera-Flores, M. y Romo-Maroto, P. (2020). Programación neurolingüística como estrategia innovadora para la didáctica de la lengua y la literatura. Revista Cátedra, $3(3), 18-32$.

\section{Resumen}

Este artículo es el resultado de una investigación cuyo enfoque es cuali-cuantitativo. El propósito fue recolectar información y datos teóricos para entender y explicar cómo la Programación Neurolingüística (PNL) puede a través de los nuevos estudios de la Didáctica de la Lengua y la Literatura (DLL) contribuir en su desarrollo. Se pretende lograr que los maestros lleguen a vincularse con el mundo de los estudiantes. Las estrategias de la PNL han sido adaptadas a las clases de Lengua de una manera didáctica y se toma en cuenta el papel de las emociones en el desarrollo del proceso de enseñanza-aprendizaje. Los datos estadísticos obtenidos mediante una encuesta descriptiva ayudaron a conocer la forma en la que los maestros trabajan con los estudiantes y cómo ellos responden al modelo de aprendizaje aplicado. Por lo tanto, se concluyó que este modelo no responde a las necesidades actuales. La propuesta planteada brinda nuevas herramientas al docente para

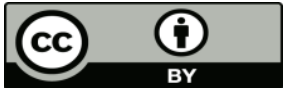


alcanzar un aprendizaje significativo tomando en cuenta las necesidades e intereses de los alumnos. Para esto el estudio se centra en las diferentes técnicas de la PNL, aplicables en el aula como: conocimiento de los sistemas representacionales que existen para sentir y conocer el mundo que nos rodea, cómo funcionan los niveles de pensamiento lógico y cómo afectan a la conducta, estrategias de rapport para sintonizar en grupo e incluso estrategias para mejorar la ortografía con la PNL.

Palabras clave

Didáctica, Lengua, Literatura, Programación Neurolingüística, rapport, sistemas representacionales.

\section{Abstract}

This article is the result of research with a quali-quantitative approach. The purpose was to collect information and theoretical data to understand and explain how Neurolinguistic Programming (NLP) can through the new studies of Language and Literature Didactics (DLL) contribute to its development. The aim is to get teachers to connect with the world of students. NLP strategies have been adapted to language classes in a didactic way and the role of emotions in the development of the teaching-learning process is taken into account. The statistical data obtained through a descriptive survey helped to understand how teachers work with students and how they respond to the applied learning model. Therefore, it was concluded that this model does not respond to current needs. The proposal proposed provides new tools to the teacher to achieve significant learning taking into account the needs and interests of students. For this, the study is centered in the different techniques of the NLP, applicable in the classroom as: knowledge of the representational systems that exist to feel and know the world that surrounds us, how the levels of logical thought work and how they affect the behavior, rapport strategies to tune in group and even strategies to improve the spelling with the NLP

\section{Keywords}

Didactics, Language, Literature, Neurolinguistic Programming, rapport, representational systems.

\section{Introducción}

La Didáctica de la Lengua y la Literatura (DLL) es una ciencia que tienen como objeto de estudio el complejo proceso de enseñar una lengua. Es indispensable para que el docente conozca las estrategias para el desarrollo de las destrezas tanto intelectuales como motrices. Además, como menciona Mendoza (2003) "la DLL se centra en la adaptación, selección y derivación de saberes lingüísticos y literarios" (p. 5). Es decir, que la DLL tiene el objetivo de alcanzar y potenciar los conocimientos y vincularlos a la experiencia y la vida diaria de los estudiantes. Así también lo reconoce Bronckart (2004)

La didáctica de la lengua es una disciplina que persigue el estudio de la lengua y la comunicación y su enseñanza en el marco del interaccionismo social en cuanto que conduce a analizar las conductas humanas como acciones contextualizadas o situadas, en las cuales las propiedades estructurales son un producto de la socialización (p. 42).

Sin embargo, la educación de hoy no solo involucra los conceptos, sino también destrezas relacionadas a los intereses y necesidades de los estudiantes, implicando sus emociones y 
su conducta. Sobre esto Romo (2017) indica que "los maestros tienen poca preparación en el desarrollo de las destrezas y se dedican más al trabajo de conceptos" (p. 21). Así también menciona Mohl (2017) "un profesor que no conozca el modo en que sus alumnos asimilan sus exposiciones, no podrá dirigir adecuadamente sus procesos de aprendizaje" (p.22). Con esto se quiere recordar que es responsabilidad tanto del docente como del sistema educativo estar listos para conocer y adaptar nuevas metodologías en beneficio de los estudiantes para alcanzar la calidad y calidez deseada. Esto también se puede observar en la Ley Orgánica de Educación Intercultural, LOEI (2011) que en su artículo 2, literal W, manifiesta:

Calidad y calidez. - Garantiza el derecho de las personas a una educación de calidad y calidez, pertinente, adecuada, contextualizada, actualizada y articulada en todo el proceso educativo, en sus sistemas, niveles, subniveles o modalidades; y que incluya evaluaciones permanentes. Así mismo, garantiza la concepción del educando como el centro del proceso educativo, con una flexibilidad y propiedad de contenidos, procesos y metodologías que se adapte a sus necesidades y realidades fundamentales. Promueve condiciones adecuadas de respeto, tolerancia y afecto, que generen un clima escolar propicio en el proceso de aprendizajes (p. 10).

Por esa razón se propone a la PNL como un anclaje que ayude a estabilizar la educación actual y a expandir la posibilidad de nuevos recursos y estrategias para identificar mejor como perciben el mundo los estudiantes, sus necesidades e intereses, de acuerdo a sus sentidos. Para desarrollar las macrodestrezas del aula: escuchar, hablar, leer y escribir, se necesita desarrollar hábilmente la competencia comunicativa. Ya Hymes en 1971 indicaba sobre la competencia comunicativa indica que:

La competencia comunicativa es el término más general para la capacidad comunicativa de una persona, capacidad que abarca tanto el conocimiento de la lengua como la habilidad para utilizarla. La adquisición de tal competencia está mediada por la experiencia social, las necesidades y motivaciones, y la acción, que es a la vez una fuente renovada de motivaciones, necesidades y experiencias (p. 31).

Al trabajar en conjunto con la PNL y la DLL se estará brindando a los estudiantes herramientas nuevas para interiorizar el conocimiento y mejorar los lazos entre docente y dicente. Sobre esto menciona Granja Palacios:

La comunicación pedagógica en la interacción docente-alumno desempeña un papel fundamental en el proceso de enseñanza y aprendizaje, donde el diálogo como forma de comunicación aporta a la transmisión, la trasferencia y la construcción del conocimiento y a la formación de una persona autónoma e independiente (2013, p. 67).

Es decir, una buena sintonía y comunicación en el aula son importantes para la formación educativa, así lo asegura Zapata (2007) “... al concientizar las formas interacciónales maestro-alumno que utilizan para llegar al conocimiento, es posible que exista mayor autogestión a la motivación" (p. 7). Al lograr despertar su interés el docente habrá roto una brecha de comunicación importante para alcanzar la empatía y afectividad necesaria para acercarse a sus estudiantes y construir los saberes de forma adecuada.

Licencia Creative Commons Atribución 4.0 Internacional (CC BY 4.0)

Revista Cátedra, 3(3), pp. 18-32, septiembre-diciembre 2020. e-ISSN:2631-2875

https://doi.org/10.29166/catedra.v3i3.2430 
Además, es importante recordar que el docente está comunicando constantemente, desde que ingresa, su actitud frente al grupo, la postura del cuerpo, tono de voz, uso de las palabras para comunicar deseos... todo comunica. Se debe tomar en cuenta que al final él es quien guía la clase y que de él depende su éxito. Es necesario que conozca herramientas que le faciliten una comunicación efectiva y afectiva, que le permita conocerse y conocer al resto. Así logrará aprovechar al máximo su habilidad comunicativa y relacionarse mejor con los alumnos, sintonizar con ellos para no solo impartir conocimientos, sino también intervenir en su comportamiento. Ya que como lo dice Ibáñez-Salgado (2011) “...los estudiantes a menudo, si no siempre, se comportan de distinta manera según como perciben las características personales de quien conduce la clase" (p. 461), por eso es importante que se tome conciencia sobre el cuerpo, cómo se está comunicando, cómo nos dirigimos, qué tono de voz y la mirada. Absolutamente todo está enviando un mensaje y es su responsabilidad asegurarse de que ese mensaje sea el que realmente quiere proyectar en la clase.

La PNL revela que una comunicación afectiva y adecuada puede lograr cambios favorables dentro del aprendizaje y es la clave para tratar asuntos como: la indisciplina, falta de interés en la materia, distractores ambientales... como mencionan Churches y Terry (2000)

la enseñanza versa tanto sobre las relaciones como sobre la pedagogía. Trata con sensaciones y con hechos y se basa sobre todo en lo que hay en el interior de tu mente y en la mente de tus alumnos. Trata del uso de tus sentidos y del conocimiento de la asignatura (2000, p. 15).

Para poder motivar de forma adecuada es necesario conocer las emociones, las formas de interpretar el mundo de cada individuo, despertar un instinto de necesidad o interés y luego transformarlo en un conocimiento real. Para poder lograrlo necesitamos de la PNL y sus herramientas.

El artículo está estructurado en cuatro partes: la primera describe las concepciones fundamentales de la PLN y la DLL requeridas para su estructuración teórica; la segunda explica los resultados estadísticos obtenidos en la aplicación de la escala descriptiva aplicada; la tercera parte presenta la discusión de los resultados más relevantes a partir de los datos estadísticos; y finalmente se dan a conocer las conclusiones fruto de las inferencias trascendentales del artículo.

\section{1 ¿Qué es la PNL?}

La PNL se la puede reconocer como un modelo de inteligencia emocional, donde se programa la mente humana por medio del lenguaje, tanto verbal y sus elementos paralingüísticos, como no verbal: postura del cuerpo y gestos faciales. Años de estudio de sus fundadores John Grinder, un profesor de lingüística y Richard Bandler (1975), estudiante de informática y matemáticas de la Universidad de California, demostraron que la mente humana funciona como una máquina, que reacciona mediante estímulos lingüísticos que generan cambios de conducta. Por esta razón es el docente quién debe fortalecer esta herramienta y aplicarla tomando en cuenta las presuposiciones de la PNL, que son:

- No se puede cambiar la conducta de otro sino cambiamos la nuestra.

- Los cambios de uno afectan al resto.

- Todo el tiempo comunicamos.

- Lo que comunicas recibes como resultado.

- Cada individuo tiene una visión distinta de la realidad. 
- Quien reconoce la perspectiva y necesidades del otro tiene el control de la comunicación.

- Asociar los recuerdos a las cosas.

- Estar seguro de lo que se hace.

- La retroalimentación es importante para reconocer los avances.

Todo lo que le rodea al ser humano lo afecta y lo compromete a ser y a comportarse de una u otra forma, el lenguaje en conclusión llega a ser el factor más dominante e influyente de todos. Según Richard Churches y Roger Terry (2009) "la programación neurolingüística es la habilidad de influir con las palabras y usar el lenguaje para crear un cambio" (p.31). Este cambio se genera cuando aprendemos a leer las emociones de nuestros interlocutores y comunicarnos de acuerdo con sus intereses y necesidades. Los maestros al trabajar con grupos de adolescentes deben tener en cuenta este aspecto que le ayuda a que los estudiantes desarrollen actitudes positivas a través de las palabras que escuchan de sus maestros. Propender un cambio de actitud en el aula cuando se den conductas inapropiadas es la labor que debe desarrollar el docente a partir de la forma de empleo del lenguaje y la manera asertiva de estimular para lograr los cambios esperados.

\subsubsection{Sistemas Representacionales}

Los sistemas representacionales van de la mano con nuestros sentidos y la forma en la que percibimos el mundo y son tres (Dobrinsky, 2007, pp. 20-25):

- Visual: Sus pensamientos son representados mediante imágenes y pueden trabajar varias ideas al mismo tiempo. Las personas visuales prefieren trabajar con gráficos y textos que puedan observar, ya que su aprendizaje está ligado a la vista, lo que implica que tienen mayor sensibilidad a los colores, figuras, sombras... son capaces de crear imágenes en su mente o recordar otras vistas antes.

- Auditivo: Sus ideas y pensamientos son abstractos y deben culminar una idea o pensamiento para seguir con la siguiente. Trabajan con su odio y pueden recordar diálogos, frases o crear unos nuevos.

- Kinestésico: Las emociones y sensaciones los gobiernan. Toman decisiones de acuerdo a cómo se sentirán, el ambiente y el lugar influenciará para poder generar ideas y concentrarse.

Los mismos Grinder y Bandler (1975) exponen que "toda experiencia interna y externa, puede codificarse como constituida por alguna combinación de estas clases sensoriales y representarse eficazmente en términos de esos sistemas" (p.21). En este caso, el docente debe reconocer e identificar el sistema representacional que manejan sus estudiantes, pues así podrá dirigirse a ellos con mayor facilidad, ya que, aunque todos poseamos todos los sentidos para interpretar la realidad, suele predominar uno sobre otro. Lo ideal en este caso sería que el profesor de literatura elabore su clase en función de estos sistemas representacionales y realice actividades que involucren los cinco sentidos dentro del proceso de enseñanza con el fin de desarrollar habilidades importantes para la comunicación.

\subsubsection{Niveles lógicos del pensamiento}

Dentro de la PNL existen una serie de procesos que sirven como una guía para el desarrollo espiritual y mental de las personas, se los llama niveles lógicos porque están organizados de forma independiente y a su vez conectados de forma secuencial y van desde el nivel menor hasta el mayor. En este caso tenemos:

Licencia Creative Commons Atribución 4.0 Internacional (CC BY 4.0)

Revista Cátedra, 3(3), pp. 18-32, septiembre-diciembre 2020. e-ISSN:2631-2875

https://doi.org/10.29166/catedra.v3i3.2430 
- Entorno: ¿Dónde y con quién?

- Conducta: ¿Qué hace?

- Habilidades: ¿Qué sabe (hacer)?

- Valores y Creencias: ¿Por qué lo hace?

- Identidad: ¿Quién soy yo?

- Espiritualidad: ¿Quién hay más allá de mí?

La PNL determina que al momento de comunicarnos debemos cumplir con la Ley de los sistemas sobre estos niveles lógicos. Esta ley menciona que, si afectas un nivel alto necesariamente estas afectando al resto de niveles. Mientras que, si afectas a un nivel inferior no estas afectando a los niveles superiores. Ejemplo:

Cuando se le dice al estudiante "eres impuntual". Se afecta su identidad, un nivel alto, dando por hecho que es impuntual y él inconscientemente lo asume como tal y no genera un cambio. Otra cosa sería decirle "llegar tarde está mal". ¿Puedes llegar a tiempo a mi clase? Este caso se dirige a un nivel inferior, la conducta. Se hace una reflexión sobre su comportamiento. Algo que puede mejorar con el tiempo y que no marca su personalidad, además de invitarle a un compromiso o una propuesta de cambio positivo.

Aprender a ser perspicaces al momento de usar la palabra es una herramienta para construir. Es necesario que antes de dirigirnos a alguien se analice que tipo de cambio se pretende lograr y luego ubicar el nivel correcto para producirlo.

Artavia (2005) reflexiona sobre la importancia de la flexibilidad del docente y del tacto pedagógico, asimismo señala que las interacciones alumno-maestro involucran afectos. Se percata de lo "necesario que son los sentimientos para las estructuras motivacionales de los estudiantes y para que el proceso de enseñanza-aprendizaje sea sano" (p. 65). Por este motivo insertar a la PNL para una comunicación efectiva - afectiva, puede resultar favorable, ya que el maestro será más cuidadoso en comunicar deseos, sin llegar a dañar niveles importantes.

\subsubsection{Técnicas y estrategias de la PNL}

Las técnicas y estrategias de la PNL buscan incentivar al estudiante por medio de actividades y dinámicas lúdicas que brindan la oportunidad de generar cambios de conducta y de aprendizaje. Además, de reconocerse como seres individuales y reconocer al otro dentro de su desarrollo cognitivo con la guía y apoyo del docente. Este aspecto, además, cumple con lo que dice la LOEI en su artículo 2, literal q:

Motivación. - Se promueve el esfuerzo individual y la motivación a las personas para el aprendizaje, así como el reconocimiento y valoración del profesorado, la garantía del cumplimiento de sus derechos y el apoyo a su tarea, como factor esencial de calidad de la educación (2011, p. 9).

Las acciones que realiza el maestro en el aula deben mejorar la motivación. Estas actividades no son desarrolladas, muchas veces por desconocimiento y falta de interés. Con el fin de mejorar los canales de comunicación entre docente y dicente se propone las siguientes técnicas y estrategias de la PNL.

\subsubsection{Afirmaciones positivas}

Esta herramienta se basa en la utilización de los niveles de pensamiento lógico. Su fin es utilizar el lenguaje de forma adecuada para construir enunciados positivos para los interlocutores e influir sobre su conducta. Nuestro cerebro está programado para hacer 
exactamente lo contrario de lo que se pide u ordena. Por ejemplo: no, pienses en flores amarillas. Sin dudarlo, el cerebro al menos imaginó las flores amarillas... Por esta razón, se recomienda evitar palabras negativas al iniciar un enunciado y construirlas tomando en cuenta en nivel de pensamiento lógico que desea motivar.

Cuando le decimos a un alumno: "no, comer en clase" - comer en clase está mal. ¿Podemos evitar hacerlo? Ambas afectan el nivel de conducta, pero la segunda, reconoce que es error e invita a la reflexión sobre un cambio. Mientras la primera solo muestra negatividad. Los estudiantes a veces necesitan interiorizar lo que está sucediendo a su alrededor, y una prohibición suele generar dudas sobre lo que puede o no hacer.

\subsubsection{Elogio periférico en el Aula}

Esta herramienta sirve para fortalecer las reglas dentro del aula, que el docente exprese sus deseos y lo que espera de la clase. Los pasos para realizarla son:

- Identificar una conducta no deseada en clase. Por ejemplo, un estudiante que nunca hace su tarea.

- Decir en voz alta "gracias a todos los que siempre hacen su tarea a tiempo y se esfuerzan por cumplir, en verdad lo valoro".

- Mientras utiliza esta frase para generalizar y agradecer el trabajo de todos es importante hacer contacto visual con el estudiante que nunca cumple con la tarea.

- Hacer esto cada vez que el estudiante incumpla y se irá notando un cambio de actitud (Marland, 1985, p.34).

Al reforzar los comportamientos positivos del grupo, afectará a quienes no cumplen con la perspectiva del docente y les ayudará a conocer lo que él busca y quiere de su clase. Daniel Goleman (1995) dice que todos estamos conectados con los demás y que es fácil para los humanos recoger las emociones internas de otros seres humanos (p. 62). Por este motivo la PNL ayuda a compartir nuestros deseos y emociones de forma clara con los estudiantes y convertirlos en objetivos y metas a alcanzar en equipo, ya que es un puente para contactarnos y conocernos.

\subsubsection{Submodalidades}

Las submodalidades están basadas en el uso de los sistemas representacionales. Generan una experiencia sensorial y emocional basada en un aprendizaje efectivo. Cuando se llega al aula de clases algunas veces los estudiantes se encuentran dispersos o cansados para iniciar con la materia. Por esta razón es necesario empezar con este tipo de ejercicios para cambiar un ambiente desagradable en uno agradable. Es vital que el docente sepa identificar el estado de ánimo del grupo y trabajar en ello. Ibáñez-Salgado (2011) reconoce que "al evaluar el contexto interaccional de un grupo-curso desde la percepción de los estudiantes, permite obtener valiosa información sobre aspectos que facilitan el aprendizaje" (p. 459). Para ello es necesario trabajar con la herramienta de submodalidades que nos brinda la PNL. Además de lograr un cambio de ambiente positivo, ayuda a hacer una clase diferente y divertida.

Un buen ejercicio para generar un cambio en el caso que los estudiantes estén alborotados sería pedirles silencio, que cierren los ojos y que respiren profundamente. Esta secuencia de respiración profunda acompañada de una música suave o de un poema, ayuda a que entren en un proceso de relajación. Además, ayuda a oxigenar la mente y disipar las energías acumuladas en el cuerpo. De igual manera si se necesita llenarlos de energía porque el salón está apagado, podemos ponerles música alegre por unos minutos o hacerles imaginar alguna situación divertida. Cosas sencillas pueden hacer de la clase un espacio diferente 
para encontrarnos con el conocimiento. Algunos aspectos a considerar para el desarrollo de esta estrategia son:

\begin{tabular}{|c|c|c|c|}
\hline Submodalidades & $\begin{array}{l}\text { Aspectos a } \\
\text { considerar }\end{array}$ & $\begin{array}{l}\text { Para mejorar una } \\
\text { experiencia } \\
\text { agradable se debe }\end{array}$ & $\begin{array}{l}\text { Cambiar una experiencia } \\
\text { negativa a positiva }\end{array}$ \\
\hline Visuales & $\begin{array}{l}\text { Tamaño o } \\
\text { posición } \\
\text { Distancia } \\
\text { Asociado o } \\
\text { disociado } \\
\text { Color } \\
\text { Foto o película }\end{array}$ & $\begin{array}{l}\text { Hacer que la } \\
\text { experiencia que se } \\
\text { imagine o recuerde } \\
\text { sea grande y } \\
\text { cercana. } \\
\text { Asociarla y hacerla } \\
\text { una película en } \\
\text { movimiento. } \\
\text { Que tenga colores } \\
\text { vivos. }\end{array}$ & $\begin{array}{l}\text { Crear una imagen } \\
\text { pequeña y lejana de la } \\
\text { situación. } \\
\text { Disociarse y hacer que sea } \\
\text { una foto. } \\
\text { Ponerla en blanco y negro }\end{array}$ \\
\hline Auditivas & $\begin{array}{l}\text { Volumen } \\
\text { Posición y } \\
\text { distancia } \\
\text { Número de voces } \\
\text { Música }\end{array}$ & $\begin{array}{l}\text { Subir el volumen, } \\
\text { agregar voces, } \\
\text { poner música }\end{array}$ & $\begin{array}{l}\text { Bajar el volumen } \\
\text { Quitar las voces y la } \\
\text { música o agregar voces y } \\
\text { música diferente. }\end{array}$ \\
\hline Kinestésicas & $\begin{array}{l}\text { Origen, } \\
\text { movimiento y } \\
\text { velocidad } \\
\text { Temperatura } \\
\text { Peso } \\
\text { Textura }\end{array}$ & $\begin{array}{l}\text { Haz que la } \\
\text { sensación tenga } \\
\text { más movimiento y } \\
\text { se extienda a todo } \\
\text { el cuerpo. } \\
\text { Cambia la } \\
\text { temperatura, peso } \\
\text { y textura de forma } \\
\text { adecuada y que } \\
\text { genere r una } \\
\text { sensación } \\
\text { agradable. }\end{array}$ & $\begin{array}{l}\text { Controla el movimiento } \\
\text { de acuerdo a la situación, } \\
\text { intenta producir un } \\
\text { movimiento suave y } \\
\text { relajante si la situación es } \\
\text { tensa o un movimiento } \\
\text { más dinámico si la } \\
\text { situación se torna } \\
\text { demasiado aburrida o } \\
\text { monótona. } \\
\text { temperatura del lugar } \\
\text { debe ser adecuada para el } \\
\text { trabajo. }\end{array}$ \\
\hline
\end{tabular}

Cuadro 1. Las submodalidades y aspectos a considerar para mejorar una experiencia. Las submodalidades nos permiten mejorar una situación, el cuadro representa los aspectos que se deben consideran para aplicarlas

El gráfico permite apreciar aspectos ya mencionados anteriormente y que nos expresan las formas adecuadas de trabajo que el docente puede realizar a partir de las submodalidades de acuerdo con las experiencias en el aula.

\subsubsection{Rapport en grupo}

Es una técnica sencilla y de rápidos resultados. Ayuda a sintonizar e influir sobre el estado de ánimo y conducta del estudiante. Para llevara a cabo el rapport se necesita que te sigan paso a paso y hagan lo mismo que tú. A criterio de los autores se sugieren algunas actividades que se han adaptado al área de Lengua y Literatura:

- Preguntas universales con respuestas positivas. Primero se debe elaborar una serie de preguntas sencillas cuya respuesta sea un sí. Ejemplo: ¿Han escuchado

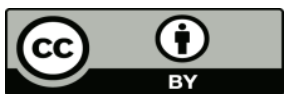


alguna vez cantar un gallo? ¿Han leído alguna vez un libro? ¿Han escuchado la radio?... Cada vez que se responda con un sí, se debe levantar la mano. Se debe lograr que todo el salón siga tanto los movimientos como en la voz, y una vez que lo haya logrado sentirá que ha sintonizado y lo estudiantes están más atentos a lo que el docente dirá a continuación.

- Ejercicios de Gimnasia Cerebral. Para llevar a cabo estos ejercicios hay que recordar que es importante dar seguimiento y guía durante la actividad. Esta herramienta es muy efectiva ya que no solo sintoniza en grupo sino ayuda a poner en funcionamiento e integrar los hemisferios cerebrales antes de introducir un tema. Es muy importante que el docente esté seguro al realizar lo ejercicios y que los haya practicado bien con anterioridad antes de exponerlos en la clase. Entre los más sencillos para empezar con esta técnica son:

- Hacer círculos en el vientre con una mano, mientras con la otra nos damos suaves golpes en la cabeza, se puede ir alternando las manos después de ciertas repeticiones.

- Con la mano izquierda hecha puño dar unos pequeños golpes en la pierna izquierda, mientras que con la mano derecha estirada deslizamos suavemente de arriba, abajo, sobre la pierna derecha, después de varias repeticiones alternar los movimientos.

- Mover el cuerpo al ritmo de la música o cantar una canción. Ambas actividades ayudan a crear sintonía siempre y cuando todos sigan a la par los movimientos, ritmo y letra. El docente debe lograr que todos participen. El contacto visual es importante para lograrlo. El éxito de la sintonía está en poder coordinar nuestras emociones y conducta con el otro. Una vez concluida la actividad se podrá constatar que los estudiantes están más animados, relajados, generando una predisposición de bienestar que se puede anclar al conocimiento. En la medida de lo posible, se debe emplear el editor de ecuaciones de Microsoft Word para crear las ecuaciones. Se debe evitar insertar las ecuaciones como imágenes.

\subsubsection{Estrategia ortográfica de la PNL}

Bandler y Grinder (2007) pudieron constatar que las personas con buena ortografía responden a un estímulo auditivo y a un campo de visión específico. Una vez que el sonido ha ingresado a su sistema, el cerebro crea la imagen mental de la palabra y luego esta es analizada por medio de los procesos sensoriales. Es decir que la información junto a un recuerdo sensorial asociado es vital para el aprendizaje. Los pasos que se proponen para conseguirlo son:

- En una cartulina escribir la palabra a enseñar o en la esquina izquierda del pizarrón.

- Ingresar un estímulo sensorial agradable a través del relato de una historia donde se sientan cómodos, seguros, confiables.

- Introducir la palabra nueva dentro del relato de manera que ellos puedan decir la palabra "sí". Ejemplo: Recuerden el día que soñaron algo hermoso, el sol brillaba, de repente se encontraron con aquello que más amaban sin saberlo, recuerdan fue una... serendipia, en este caso esta sería la palabra motivo de estudio.

- Mientras se genera la sensación, se sujeta la tarjeta en lo alto al lado derecho para que se ubique en el campo de visión izquierdo de los estudiantes. Esta situación es la adecuada para generar en su interior la imagen mental de la palabra.

- Se indica que visualicen la palabra, luego cierren los ojos y la recreen en su mente. Una vez que todos los estudiantes aseguren que tengan la palabra en su interior se les pide que le cambien de color la palabra o que le decoren a su gusto. Se puede 
utilizar las submodalidades en este punto y se les pide que no dejen de ver a la palabra hasta que esté clara.

- Se gira la tarjeta dejándola en blanco, con los ojos de los estudiantes en la misma posición, se pide que deletreen la palabra imaginando que aún sigue ahí escrita.

- Repetir y guiar el proceso las veces necesarias (p. 9-10).

Como se puede constatar la PNL parte de una experiencia sensorial almacenada en nuestro cerebro y anclada a un conocimiento específico. La necesidad de vincularla con la docencia se debe a que las clases son el espacio propicio para conjugar todo lo que vemos, oímos, escuchamos y almacenamos.

\section{Metodología}

Partiendo del contexto anterior, la finalidad de la investigación desarrollada es conocer el modelo de la programación neurolingüística y sus beneficios en la asignatura de Lengua y Literatura. Para abordar este objetivo se llevó a cabo un estudio descriptivo.

El enfoque utilizado en esta investigación es cuali-cuantitativo, ya que parte de la recolección de información necesaria para reconocer las estrategias y técnicas de la PNL aplicables en el aula y además cuantitativa porque se realizó una encuesta a manera de escala descriptiva para identificar las herramientas que utiliza el docente para iniciar y desarrollar su clase.

\subsection{Partcipantes}

Estudiantes de la "Unidad Educativa Salamanca, Sección Vespertina" de primero de bachillerato paralelo "A" y "B" con un total de 21 estudiantes.

\section{Resultados}

se tomaron 6 preguntas significativas que relacionan la PNL con la actividad didáctica de los maestros en el aula.

Ítem 1: Considera que el docente planifica su clase en función de los diferentes estilos de aprendizaje (visual, auditivo, kinestésico). Este aspecto refleja la forma de planificar del maestro en función de los aspectos básicos relacionados con el estudiante y sus diferentes estilos de aprendizaje.

\begin{tabular}{lrr}
\hline Alternativa & Frecuencia & $\%$ \\
\hline Siempre & 1 & 4,7 \\
Casi siempre & 3 & 14,3 \\
A veces & 9 & 42,9 \\
Nunca & 8 & 38,1 \\
TOTAL & 21 & 100 \\
\hline
\end{tabular}

Cuadro 2. Estilos de aprendizaje

El ítem 1 determina que el 4, $7 \%$ de los estudiantes consideran que el docente siempre planifica su clase en función de los diferentes estilos de aprendizaje, es decir, visual, audito y kinestésico. El 14, 3 \% de los estudiantes reconoce que casi siempre el docente desarrolla esta actividad en su planificación. El 42,9\% determina que a veces el docente planifica en base a los estilos de aprendizaje, mientras que el $38,1 \%$ restante afirma que nunca sucede.

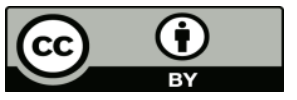


Ítem 2: El docente inicia su clase con actividades dinámicas para crear un ambiente agradable de aprendizaje. Esta pregunta tiene que ver con la capacidad didáctica del maestro de generar un ambiente distinto al iniciar la clase y propender al desarrollo animado del proceso educativo.

\begin{tabular}{lrr}
\hline Alternativa & Frecuencia & $\%$ \\
\hline Siempre & 3 & 14,3 \\
Casi siempre & 4 & 19 \\
A veces & 8 & 38,1 \\
Nunca & 6 & 28,6 \\
TOTAL & 21 & 100 \\
\hline
\end{tabular}

Cuadro 3. Ambiente agradable.

En el ítem 2 se observa que el 14, $3 \%$ de los estudiantes consideran que el docente siempre inicia la clase realizando dinámicas que generan un ambiente agradable para el aprendizaje. El $19 \%$ de los estudiantes reconoce que casi siempre el docente realiza este tipo de actividades. El 38,1\% determina que a veces el docente realiza diferentes actividades lúdicas que favorecen el trabajo en clase, mientras que el 28,6 \% restante afirma que nunca sucede.

Ítem 3: El docente realiza actividades que estimulen los hemisferios cerebrales. Como se ha visto en el desarrollo teórico el estimular los dos hemisferios cerebrales produce que se activen las partes lógicas y creativas del ser humano.

\begin{tabular}{lrr}
\hline Alternativa & Frecuencia & $\%$ \\
\hline Siempre & 2 & 9,5 \\
Casi siempre & 2 & 9,5 \\
A veces & 4 & 19 \\
Nunca & 13 & 61 \\
TOTAL & 21 & 100 \\
\hline
\end{tabular}

Cuadro 4. Ambiente agradable

Con respecto al ítem 3 se puede observar que el 9,5\% de los estudiantes consideran que siempre al iniciar la clase el docente realiza actividades que estimulen los hemisferios cerebrales como la gimnasia cerebral. El 9,5\% reconoce que casi siempre el docente realiza este tipo de actividades. El 19\% determina que a veces el docente realiza actividades que estimulen los hemisferios cerebrales, mientras el $61,9 \%$ restante afirma que nunca sucede.

Ítem 4: El docente reconoce el trabajo realizado en clase, y elogia los logros alcanzados por el estudiante. Este aspecto nos ayuda a considerar las actitudes de motivación que desarrolla el docente para lograr estímulos positivos y tomar en cuenta el elogio como elemento clave de la PNL.

\begin{tabular}{lrr}
\hline Alternativa & Frecuencia & $\%$ \\
\hline Siempre & 2 & 9,5 \\
Casi siempre & 2 & 9,5 \\
A veces & 4 & 19 \\
Nunca & 13 & 61 \\
TOTAL & 21 & 100 \\
\hline
\end{tabular}


Con respecto al ítem 4 se puede observar que el 4,8\% de los estudiantes consideran que el docente reconoce el trabajo realizado en clase, y elogia los logros alcanzados. El 28,6\% considera que el docente casi siempre reconoce su trabajo y felicita los logros. El 47,6\% determina que a veces el docente resalta el trabajo en clase, mientras el $19 \%$ restante afirma que nunca sucede.

Ítem 5: Al finalizar la clase logra recordar los conocimientos aprendidos y relacionarlos con su estado de ánimo, es decir recuerda cómo se sintió, lo que escucho, lo que vio, durante la clase, relacionándolo con el conocimiento impartido por el docente.

\begin{tabular}{lrr}
\hline Alternativa & Frecuencia & $\%$ \\
\hline Siempre & 2 & 9,5 \\
Casi siempre & 3 & 14,3 \\
A veces & 12 & 57,1 \\
Nunca & 4 & 19 \\
TOTAL & 21 & 100 \\
\hline
\end{tabular}

Cuadro 6. Aprendizaje significativo.

Con respecto al ítem 5 se puede observar que el 9,5\% de los estudiantes afirma que al finalizar la clase logra recordar los conocimientos aprendidos y relacionarlos con su estado de ánimo, es decir recuerda cómo se sintió, lo que escuchó, lo que vio, durante la clase, relacionándolo con el conocimiento impartido por el docente. El 14, $3 \%$ asegura que casi siempre recuerda la temática que vio en clase, vinculado a como se sentía. El 57, 1\% determina que a veces logra relacionar sus recuerdos en el aula con sus emociones, mientras el 19\% restante afirma que nunca sucede.

Ítem 6: Luego de la clase ha interiorizado el conocimiento y lo relaciona con su vida diaria. Se siente motivado y seguro de lo aprendido. La aplicabilidad práctica de lo que se aprende genera en los estudiantes una motivación interna. Al sentir que lo aprendido tiene una utilidad práctica y que le sirve para su vida hace que se incorporen sus aprendizajes a sistemas intelectuales de largo plazo.

\begin{tabular}{lrr}
\hline Alternativa & Frecuencia & $\%$ \\
\hline Siempre & 4 & 19 \\
Casi siempre & 5 & 23,8 \\
A veces & 9 & 42,9 \\
Nunca & 3 & 14,3 \\
TOTAL & 21 & 100 \\
\hline
\end{tabular}

Cuadro 7. Motivación por lo que aprendió

Con respecto al ítem 6 se puede observar que el $19 \%$ afirma que al finalizar la clase ha interiorizado el conocimiento y lo relaciona con su vida diaria. Se siente motivado y seguro de lo aprendido. El 23,8 \% asegura que casi siempre concluye la clase motivado y seguro de lo aprendido. El 42,9\% determina que a veces terminó la clase sintiendo que aprendió, mientras el 14,3\% restante afirma que nunca sucede.

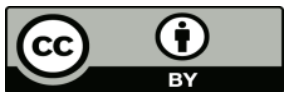




\section{Discusión de los resultados}

La planificación didáctica es fundamental para el trabajo en el aula. Por ello, es importante que el docente tome en cuenta los diferentes estilos de aprendizaje de los alumnos para que el conocimiento llegue a todos. El uso de imágenes, audios e incluso la disposición del aula son elementos que promueven el aprendizaje en función de cada estilo de aprendizaje. El profesor debe tomar en cuenta estos factores para asegurar que el conocimiento esté al alcance. Sin embargo, los resultados obtenidos no son satisfactorios, porque perciben que el maestro trabaja en función de lo que él cree es el aprendizaje sin tomarlos en cuenta.

Crear espacios nuevos de aprendizaje por medio de diferentes actividades dinámicas es importante para acompañar el conocimiento. Esto ayuda a romper las barreras de la educación tradicional. El docente es el encargado de generar un ambiente donde los estudiantes disfruten lo que aprenden. Sin embargo, no están motivados hacia el aprendizaje como una experiencia agradable.

La PNL desarrolla ejercicios de estimulación cerebral que ayudan a generar Rapport para activar zonas del cerebro, conectar nuevas ideas y estar atentos. Iniciar la clase con este tipo de actividades brinda al docente un mejor control y actividad durante la clase. Los resultados obtenidos no son satisfactorios, porque no están conectados con el maestro al comenzar la clase y carecen de estimulación que le facilite adquirir nuevos conocimientos.

La PNL crea sintonía en el aula de clase lo que es indispensable para una buena comunicación con el docente. Para esto existen algunas técnicas, entre ellas encontramos el elogio periférico que ayuda a comunicar aquello que se desea de forma positiva, elogiando y reconociendo los logros alcanzados para que sean conscientes de sus avances. Sin embargo, estos resultados no se alcanzan porque no se da a conocer los logros de aprendizaje que le permitan la autoevaluación y conocimiento de su desempeño.

Las representaciones internas dentro de la PNL ayudan a asociar una determinada emoción con un recuerdo o aprendizaje nuevo ya que está comprobado que las emociones ayudan a recordar hechos. Los resultados indican que dentro del aula no se vinculan experiencias agradables al conocimiento, por lo tanto, tendrán dificultad en pasar los conocimientos a la memoria de largo plazo.

La Didáctica de la Lengua y Literatura sostiene que es importante mejorar la comunicación entre el docente y el estudiante con el fin motivar y dinamizar la clase. Los resultados obtenidos nos indican que las clases que reciben los alumnos no logran que interiorice los conocimientos y menos que se sienta seguro de lo aprendido. Esta sección del artículo es opcional.

\section{Conclusiones}

La conexión entre la Didáctica de la Lengua y la Literatura y la Programación Neurolingüística en la educación actual debe ser una prioridad en la formación de los docentes. Al existir esta desconexión los estudiantes no sienten interés por la asignatura y no desarrollan aprendizajes significativos. Es fundamental que se tengan en cuenta las emociones en el aula y se trabajen los hemisferios cerebrales.

Formar a los docentes en actividades lúdicas y significativas es clave para que se retome la educación como un espacio de trabajo agradable. Se debe compartir entre los integrantes para generar una verdadera comunidad educativa.

Licencia Creative Commons Atribución 4.0 Internacional (CC BY 4.0)

Revista Cátedra, 3(3), pp. 18-32, septiembre-diciembre 2020. e-ISSN:2631-2875

https://doi.org/10.29166/catedra.v3i3.2430 
Las actividades de PNL se pueden conectar con el área de Lengua y Literatura por las destrezas claves de la formación humana que esta desarrolla. Buscar esa interconexión de las actividades propias del área con las estrategias significativas que generan interconexiones cerebrales ayuda a los estudiantes a sentirse en un ambiente educativo agradable. Este factor desencadena un aprendizaje centrado en sus necesidades e intereses.

El sentirse respetado y valorado a través de las actividades de aprendizaje debe ser el motor de la educación en la actualidad. Una persona responde mejor cuando siente que los otros valoran su esfuerzo y trabajo. Eso se logra cuando el maestro emplea estrategias de la PNL durante los tres momentos de la clase: inicio, desarrollo y finalización. El cambio educativo requiere de docentes que deseen cambiar las estructuras verticales por formas de comunicación auténticas y basadas en el respeto, trabajo y fomento del talento humano de toda la comunidad educativa.

La PNL ayuda al desarrollo de las emociones en la clase y esta compaginada con la DLL ya que forman un soporte clave y fundamental para lograr mejores seres humanos. Se cimienta la personalidad del estudiante sobre la base de competencias comunicativas que le permitan desenvolverse adecuadamente en cualquier campo de la vida.

\section{Bibliografía}

Artavia Granados, J. M. (2005). Actitudes de las docentes hacia el apoyo académico que requieren los estudiantes con necesidades educativas especiales.

Bronckart, J. P. (2004). Actividad verbal, textos y discursos: por un interaccionismo sociodiscursivo. Fund. Infancia y Aprendizaje.

Bandler, R., \& Grinder, J. (1975). The structure of magic (Vol. 1). Palo Alto, CA: Science and Behavior Books.

Churches, R., y Terry, R. (2000). PNL para profesores: cómo ser un profesor altamente eficaz. Editorial Desclée de Brouwer.

Churches, R., y Terry, R. (2009). PNL para profesores. Cómo ser un profesor altamente eficaz. Bilbao: Desclée De Brouwer

Dobrinsky, M. (2007). PNL . Ediciones LEA.

Ejecutiva, F. (2011). Ley Orgánica de Educación Intercultural. Segundo Suplemento del Registro Oficial. http://www. wipo. int/edocs/lexdocs/laws/es/ec/ec099es. Pdf

Goleman, D. (1995). Emotional intelligence. New York, NY, England.

Grinder, J., y Bandler, R. (2007). De sapos a príncipes: Transcripción del seminario de los creadores de la PNL. Editorial Cuatro Vientos.

Hymes, D. H. (1971). «Acerca de la competencia comunicativa». En Llobera et al. (1995). Competencia comunicativa. Documentos básicos en la enseñanza de lenguas extranjeras. Madrid: Edelsa.

Ibáñez-Salgado, N. (2011). Aprendizaje-enseñanza: mejora a partir de la interacción de los actores. Educación y educadores, 14(3), 457-474. 
Ley Orgánica de Educación Intercultural. Registro Oficial del Ecuador. Quito, Ecuador. 31 de marzo de 2011.

Marland, M. (1985). El arte de enseñar:(técnicas y organización del aula) (Vol. 10). Ediciones Morata.

Mendoza A. (2003). Didáctica de la Lengua y la Literatura. Madrid: Prentice Hall.

Mohl, A. (2017). El aprendiz de brujo. Editorial Sirio S. A.

Palacios, C. G. (2013). Caracterización de la comunicación pedagógica en la interacción docente-alumno. Investigación en enfermería: Imagen y Desarrollo, 15(2), 65-93.

Romo, Pablo (2017). Didáctica de la comunicación oral. Ediciones Ecuafuturo. Quito

Zapata, J. (2007). Análisis del proceso enseñanza-aprendizaje en la interacción maestroalumno. Congreso El papel de la educación en la construcción de las sociedades del conocimiento, Universidad Autónoma de Nuevo L

\section{Autores}

MICHELLE RIERA-FLORES obtuvo su título en Licenciada en Ciencias de la Educación mención Ciencias del Lenguaje y Literatura por la Facultad de Filosofía, Letras y Ciencias de la Educación de la Universidad Central del Ecuador (Ecuador) en 2019.

Actualmente es docente de Lengua y Literatura en la Unidad Educativa Particular Córdova y lleva a cabo un proyecto llamado "Mi fábrica de sueños" es una auto publicación de cuentos infantiles, con el fin de incentivar la lectura en los más pequeños mediante la elaboración de cuentos personalizados con el nombre de los niños

PABLO ROMO-MAROTO es doctor por la Universidad de Alicante - España con un estudio sobre la Didáctica de la Comunicación Oral.

Actualmente es director y docente de la Carrera de Pedagogía de la Lengua y la Literatura de la Facultad de Filosofía en la Universidad Central del Ecuador. Se ha dedicado al estudio de la Didáctica de la Lengua y la Literatura y sus artículos se han publicado en varias revistas educativas nacionales e internacionales. 